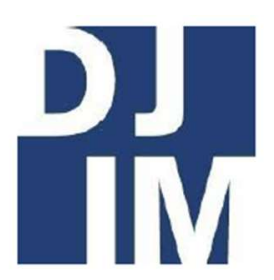

\title{
Volume 16
}

Spring

2021

ojs.library.dal.ca/djim

\section{Balancing Print and Electronic Collections in Public Libraries: Perspectives for a Changing World}

\author{
Cassandra Larose
}

School of Information Management, Faculty of Management, Dalhousie University

\begin{abstract}
Public libraries are of vital importance to their communities, providing access to information, shelter, services, and serving as an anchor for economic and social growth. As public libraries adapt to an increasingly digital world, they must address the balance of print and electronic materials to ensure that users have access to what they want and need. While public libraries' print collections are decreasing at a slower rate than those of their academic counterparts, they are also facing increasing pressure to offer materials electronically. Public libraries must address challenges in tracking usage statistics as well as their users' attitudes towards ebooks and print materials. Resource issues must be addressed, including costs and staffing. An increased desire for flexible space within library branches may also be a consideration impacting print collections. In addressing issues of accessibility, both print and electronic materials may create barriers in some instances while increasing access in others. The closure of many public library spaces during the COVID-19 pandemic in 2020 has introduced new issues, including limitations to access of print materials, new ease of access to online materials, and additional resource limitations as libraries work with limited budgets and staff. While the shift to online services during the COVID-19 pandemic has likely sped up the transition to increasing availability of online resources in public libraries, an appetite for print materials remains.
\end{abstract}

Keywords: collection management, public libraries, ebooks, libraries 


\section{Public Libraries}

Public libraries are an important public space, providing users with more than just information. Public libraries offer a space for people to gather, to spend time, and to meet. They offer a space where people can safely shelter and access resources, beyond the traditional idea of physical materials to include computer and internet access, programs and services, and nontraditional circulating items such as sporting equipment, musical instruments, and electronic devices (Federation of Ontario Public Libraries, 2018). Public libraries are considered anchor institutions in their communities, inviting economic growth and promoting social wellbeing (de la Peña McCook, \& Bossaller, 2017). Given their importance to communities and the public good, it follows that libraries must respond to changes in technology and the wants and needs of their users. This review will focus on library collections of print and electronic materials, addressing the factors that must be considered when balancing these items in a world where access to electronic materials and the apparent desire for information to be available online is increasing. Further, issues in collections management arising from the COVID19 pandemic will be addressed.

Library collections, originally comprised of physical items with many print items, are now comprised of a mix of print and electronic resources in different formats. With the shift to an ever-expanding digital landscape in information management, there are pressures to meet the needs of users expecting to be able to access materials online, while also ensuring that print materials remain accessible for those who need or prefer them.

Academic libraries tend to have robust electronic collections, including access to periodicals and other content in digital packages, with decreasing print acquisitions. In contrast, public libraries tend to still hold large print collections that are not being diminished at the rate of those of academic libraries. At the same time, they also have a growing number of materials and variety of item types in their electronic collections (Breeding, 2019).

In identifying how to balance print and electronic collections, public libraries must consider the needs and preferences of their users, their resources, and accessibility issues. While a shift to increasing electronic resource availability seems inevitable as technology continues to improve, the current COVID-19 pandemic that has caused closures of many physical library spaces may also have an impact on the magnitude and speed of this shift. Though electronic collections at public libraries increasingly include more item types than just ebooks, such as streaming films and audiobooks, 
this paper will focus generally on print and electronic reading materials.

\section{User Considerations}

In considering how to balance collections of reading materials between print and electronic formats, public libraries must assess their users' needs and preferences. To do so, they are likely to use circulation statistics to identify how and when different formats are being accessed by their users. Circulation statistic gathering methods will necessarily differ between the two formats. For print items, the library may use a software system to track circulation but may also assess how users interact with the physical materials within a location. For example, while they may collect usage statistics based on how frequently a physical item is checked out within the library's circulation system, there is also the benefit of identifying when users might be browsing and using items within the library. This includes reference materials or other items that don't circulate, as well as items that may be being used within the space during a user's visit. Although these items are being used, the fact that these uses don't result in the item being checked out electronically within the circulation system means that this usage may not be quantified and tracked. Electronic items may be tracked by the system with which the library provides access to these materials. One study of user preferences in public libraries in Chicago Balancing print and electronic collections noted that while circulation statistics for print items were easy for staff to obtain, those for electronic items were much more difficult to obtain based on the time and processes required, and some statistics, including those for electronic items that were held by a consortia of libraries rather than one library system, were unable to be identified at all (Gao and Isaia, 2017).

Breeding (2019) notes that many academic libraries use comprehensive resource management technology to manage their lending resources, platforms that allow digital materials to be accessed by users from the same interface as where they find information on availability of print resources. In contrast, public libraries are more often using integrated library systems (ILS) that require an additional service to manage loans of digital materials, such as Overdrive. As suggested in the Gao \& Isaia (2017) study, this may impact the ability to collect circulation or usage statistics that are easily comparable to statistics from their ILS systems for print materials. Thus, it may be more difficult to assess the usage and popularity of electronic titles in comparison to print materials.

Public libraries also need to consider their users' preferences and perceptions about electronic materials. Considering ebooks, as public libraries began incorporating these into their collections, there was argument about their relevance 
(Tribune Wire Reports, 2015). As ebooks may take away a share of the budget previously allocated to print materials, some argued for the purity of the physical book as a hallmark of the traditional library experience. It was noted that research showed that reading print items offers a more immersive experience than digital, and some market research suggested a levelling off of e-reader sales after an initial wave of popularity following their introduction to the market (Tribune Wire Reports, 2015). Alternately, some users embrace ebooks as an easy method of accessing materials and welcome their introduction to library systems as a way of ensuring the continued relevance of libraries as the world becomes a more digital place (Tribune Wire Reports, 2015). In addition to usage statistics, libraries may need to consider assessing user preferences in other ways, such as surveys, focus groups, and outreach to their target communities.

\section{Resources}

Costs are an important factor in the balancing of print and electronic collections in public libraries. Ebooks can cost several times more than print copies of the same title (Johnson, 2014, p. 195). One study assessing title costs across multiple schools found that on average, digital versions of books being published by academic presses was double that of the same title in a print format (Rao, Tripathi, \& Kumar, 2016). This price disparity is not unique to academic libraries. Blackwell, Mason, \& May (2019) report on a review of three large vendors of titles for public libraries in the United States and Canada, noting that the prices of titles in ebook format can highly vary between these vendors, and that ebook versions of current bestsellers may be priced with a substantial markup. While substantial variation was noted amongst titles and vendors, with some ebook titles costing less than their print counterparts, overall ebooks were priced higher than print versions by these vendors.

Licensing terms may vary by publisher, and not all popular titles may be available for licensing. Further, for some titles, limited copies may be made available for libraries to add to their catalogues, which may cause issues of access for users. Licensing terms for ebooks may also mean that the books are available for a limited amount of time, requiring libraries to pay again at the end of a period to continue offering the same titles (Johnson, 2014, pp. 19-20). Vendors may also change their own agreements and add or remove titles. A book that has been previously available in electronic format to a public library may be removed without notice depending on the terms of vendor agreements. If a library cancels or changes an agreement, they may also lose access to items that have previously been paid for and available to their users (Sendze, 2012). 
Print items have their own set of cost considerations. In addition to purchasing costs, print materials must be handled by library staff, including cataloguing and processing, shelving, returns, and repairs. Many public libraries are facing shrinking budgets and may have fewer staff members available to process book returns than in years previous. To combat these issues, many libraries have turned to technology to assist in processing returned materials. Enis (2018) reports on one library that has employed an automated system to check in and sort returns, noting that while concerns of staff layoffs were initially noted, the library has instead been able to shift staff duties to complete more public-facing tasks, providing better service to users.

Reference collections are another aspect of collections management that are being impacted by limitations on resources. Where libraries may have previously required a large amount of shelf space to house reference books, many of these materials are now available in electronic format. Although it appears that the shift to electronic reference material clearly impacts public libraries as well as academic libraries, peer-reviewed articles on this subject within Ebsco's Library Literature \& Information Science Full Text database appear to favour academic library research. Unlike academic or special libraries, where reference materials may only be required to cover specific subject areas, public libraries have a larger user base and must try to have reference materials available to cover a wide range of topics. Puacz (2005) suggests that reference librarians within public libraries are well-suited to identify which resources are most-used and look for electronic versions of these materials. In addition to the collection of reference books that one would normally find in a public library, Puacz (2005) suggests that electronic resources are now available to serve users who may have previously been required to attend a library branch to speak with a reference librarian. In addition to ebook versions of popular reference books, such as guidebooks or standard texts for a specific field, online directories have now often replaced print versions of these same items.

By removing some of the print items from a reference collection, space may be freed up within a library branch, allowing for reallocation for use as meeting rooms, public space, or new library programming or service areas. As reference items are generally non-circulating and cannot be removed from the library, providing access to them remotely via online resources may remove a barrier and increase usage. Terrell (2015) notes that a number of studies of both academic and public library collections found that print reference collection usage is low, with some of the institutions 
reporting that as little as eight to $13.5 \%$ of their print reference collections were accessed within a one-year period. In a review of reference collections management practices at member institutions in Canada and the United States of the Association of Research Libraries, King (2012) notes that most institutions consider their print reference collections to be too large. Terrell (2015) suggests that reducing the size and physical footprint of print reference collections within the library benefits both the library patrons and the collection quality. Taking the time to carefully weed print collection to include only the most high-quality and high-usage items can make the experience of browsing or searching through the print collection more valuable and less difficult for patrons. By reducing size, physical space can be allocated to higher-impact activities. In considering how to provide high-impact access to materials, Puacz (2005) suggests that libraries should consider digitizing reference resources relating to local history, allowing for promotion of these materials, broadened access and use, and ensuring their preservation.

\section{Accessibility}

Collections, whether print or electronic, must be made accessible to their users to be useful. Print items within a public library collection may be made accessible to users who are unable to attend a library in person by services such as bookmobiles, pop-up libraries, or delivery services. Print books are accessible for users who attend public libraries in person, and the ability to browse the library stacks to discover print materials may be perceived as a benefit for many library users. A print book can be accessed by a user with no additional technology requirements, while electronic resources may require software, hardware, and training to use in addition to access to the internet. However, print books may also introduce barriers for users with vision impairments that electronic materials may be able to alleviate with functions like text-to-speech or adjustable text and brightness options.

Electronic materials may pose several barriers to accessibility. There is a potential economic barrier that may affect many public library users. Systems like Overdrive, a digital resources platform used by over 65,000 libraries and their Libby app allow users to access ebooks on a web browser, tablet, or cell phone (Overdrive, n.d.). E-readers are also a popular way to read ebooks. However, all these methods require users to have access to these devices. Some users may not have access to these devices at home, nor the ability to purchase these devices due to financial constraints. While public libraries generally offer free internet access and computer use for the public, this is not a useful way to connect readers with ebooks that would 
allow them to read for prolonged periods of time.

Some public libraries may offer loans on ereaders, which is a potential way to remove this barrier for users (Gray \& Howard, 2017). An additional layer to this barrier surrounds the different models of e-readers. The popular Kindle e-reader has in the past been incompatible with some library lending systems, meaning that some users may already own an ereader only to discover that they cannot use it to access free materials available through their public library (Leech, 2013). As of this writing, only ebooks borrowed through Overdrive in the United States can be accessed on Kindle devices (Overdrive, 2021).

Conversely, electronic materials may also remove some barriers to access. While there are technological requirements to access ebooks, most lending models used for this type of material will automatically return loans at the end of the loan period. This removes the risk of fines, which can be a barrier that prevents users from continuing to access materials from the library (Gray \& Howard, 2017). Juxtaposed with the ways that print materials may be most accessible to some, electronic materials may be most accessible to others. Electronic materials can be accessed remotely, meaning that users who have transportation or mobility issues, or other factors that mean they cannot travel to a library branch, can access these materials from wherever they are if they have access to the internet.

Another positive aspect of electronic materials is the ability to access them with relative anonymity. While automated self-service machines are available at many public libraries, allowing users to retrieve and check out their own print materials without needing to present their items to library staff, there is a lack of anonymity in attending the physical library to browse or check out materials. Some users may find this to be a barrier if they are accessing materials that they consider to be sensitive, such as self-help books or books they feel embarrassed to be reading. Electronic materials remove this barrier in so much as they do not require any human interaction, and the transaction can be made in as much privacy as the user would like. Gray and Howard (2017) noted one example of this in assessing how young adult ebooks appeared to be very popular amongst library users, but not necessarily teens, as they identified that many adults were checking out these titles. They suggest that the anonymity of the ebook process may be a main driver of this, as some adults may feel embarrassed to visit a library branch and browse through the young adult section, which is often located near children's materials and populated by children and young adults. The ability to 
obtain these items online may allow some users to browse and search for books they would otherwise avoid if only available through a library visit.

\section{COVID-19 Pandemic Impacts}

The COVID-19 pandemic has introduced new pressures into the public library landscape. Libraries around the world were forced to close when cases of the COVID-19 virus rose, and some currently remain fully closed to the public. Others remain closed in terms of physical spaces and branches, but are offering online services, including the lending of ebooks and other resources that may be accessed using an internet connection (IFLA, n.d). During the closures, many libraries implemented online library card signups, allowing users to obtain an account to access electronic materials through the libraries' websites even while physical branches were closed (American Library Association, 2020). Simplifying the process of obtaining a library card may have enticed new users to access library materials.

Accessibility issues are even starker than usual when considering how public libraries have fared during the pandemic. The results of a survey by the Public Library Association released in April 2020 suggested that more than 20 million people in the United States do not have access to broadband internet service in their home (American Library Association, 2021). In Canada, the Canadian Radio-television and Telecommunications Commission reports that only $87.4 \%$ of households have broadband service, with the percentage dropping to $45.6 \%$ in rural communities (Canadian Radio-television and Telecommunications Commission, 2021). The availability of internet access at public library branches is likely a draw for many users, and those without internet access at home, or those experiencing homelessness without reliable public internet access may be unable to utilize electronic collections during building closures.

Some public libraries have reopened with restrictions on the lending of their physical collections. Many have implemented a quarantine period on returned materials. For example, a library may hold a returned item for 72 hours to ensure that there is no contagion on the item before placing it back into circulation (IFLA, n.d.). While less of an imposition than the complete closure of the library branch, this does have an impact on the availability of print items. Within Nova Scotia, some libraries worked to ensure that print items could still be delivered to users during closures, offering contactless pickup options or home delivery. The South Shore Public Libraries noted the importance of print items to their users, many of whom are elderly or lack reliable home internet service (Moscovitch, 2020). 
Libraries are likely to face additional budget restraints given the realities of the COVID-19 pandemic, and as such, it is likely that difficult decisions will need to be made about how to invest funds in both print and digital collections. A recent reading habits study by the PEW Research Centre as well as records of book sales from retailers suggests there is still a preference for print materials by the public (Breeding, 2020b). It follows that public libraries will continue to offer print materials as they reopen around the world. However, given the focus on providing mostly electronic resources during library closures, it seems likely that these more robust resource bases will continue to be made available even after libraries return to offering full services. Despite higher costs, the ability for public libraries to continue providing services to users during a global crisis shows that these materials can be useful in planning for emergencies where physical library services are unavailable (Breeding, 2020b).

\section{Conclusion}

Balancing print and electronic collections in public libraries requires collections managers to assess multiple factors. User preferences and habits must be regularly assessed to ensure that the materials available are meeting the needs of library users. Resource limits also influence the balance of material types. Print items may be less expensive to purchase but require more Balancing print and electronic collections human intervention in terms of staffing and more physical space within the library, where shelf space is often decreasing to meet other needs. Electronic materials present a higher cost and require staff resources, as well as technology requirements. Libraries must also consider how materials will be accessed by their users and whether there are any barriers to access when choosing how to allocate limited resources. This also requires libraries and system vendors to address gaps in statistics and identify ways to better measure usage. While electronic materials may remove some barriers for users, they also introduce barriers for some. Public libraries must consider how to ensure print and digital materials are accessible to the users who want them, regardless of factors such as physical ability and socioeconomic status.

The closure of many physical library spaces during the COVID-19 pandemic may have helped to speed the transition to increasing proportions of electronic materials in public library collections. However, the nature of public libraries as spaces that welcome all members of the public means they will likely always have print materials as a part of their collections (Breeding, 2020a). The rapid requirement for libraries to shift to focusing on online offerings may change attitudes towards digital materials to be more favourable. This rapid shift has also provided valuable information on the 
capabilities of public libraries to offer robust electronic resources to users. Considering this, public libraries are likely to invest more resources in improving online delivery services and materials moving forward.

\section{References}

American Library Association (April 9, 2020).

Public libraries launch, expand services during COVID-19 pandemic. Retrieved

October 22, 2020, from

http://www.ala.org/news/press-

releases/2020/04/public-libraries-launch-

expand-services-during-covid-19-

pandemic-0

Blackwell, M., Mason, C., \& May, M. (2019).

Ebook availability, pricing, and licensing:

A study of three vendors in the U.S. and

Canada. Computers in Libraries, 39(9), 20-

28.

Breeding, M. (2019). Smarter libraries through

technology: Balancing print and digital.

Smart Libraries Newsletter, 39(06), 1-2.

Breeding, M. (2020a). A global crisis may reshape library services. Computers in Libraries; Westport, 40(4), 9-11.

Breeding, M. (2020b). The stark reality of COVID-19's impact on libraries:

Technology for the new normal. Computers in Libraries, 40(6), 910.
Canadian Radio-television and

Telecommunications Commission (2021, March 19). Broadband fund: Closing the digital divide in Canada. Retrieved March 29, 2021, from https://crtc.gc.ca/eng/internet/internet.h tm

de la Peña McCook, K. \& Bossaller, J.S. (2017). Introduction to public librarianship. American Library Association. ProQuest Ebook Central, https://ebookcentral.proquest.com/lib/d al/detail.action?docID=5964195.

Enis, M. (2018). Materials on hand. Library Journal, 143(9), 21.

Federation of Ontario Public Libraries. (2018, October 4). Non-traditional circulating library collections. Retrieved March 29, 2021 from http://fopl.ca/news/nontraditional-circulating-library-collections/

Gao, Y., \& Isaia, M. (2017). Reading and the good life: An analysis of print and digital readers in suburban libraries. Library Philosophy and Practice; Lincoln, 1-18.

Gray, R., \& Howard, V. (2017). Young adult use of ebooks: An analysis of public library services and resources. Public Library Quarterly (New York, N.Y.), 36(3), 199212.

IFLA (n.d.). COVID-19 and the global library field. Retrieved October 22, 2020, from 
https://www.ifla.org/covid-19-and-

libraries

Johnson, P. (2014). Fundamentals of collection development and management. American Library Association.

King, N. (2012). Nice vs. necessary: Reference collections in ARL member libraries. The Reference Librarian, 53(2), 138-155.

Leech, H. (2013). Car crash e-lending: Help is on the way? Multimedia Information \& Technology, 39(4), 15-18.

Moscovitch, T. (2020, May 10). Libraries on overdrive: They've ramped up digital services during the pandemic, but the future remains uncertain. Halifax Examiner. Retrieved October 22, 2020, from https://www.halifaxexaminer.ca/featur ed/libraries-on-overdrive-theyveramped-up-digital-services-during-thepandemic-but-the-future-remainsuncertain/

Overdrive. (n.d.). Who we are - Overdrive. Retrieved March 29, 2021 from https://company.overdrive.com/compa ny-profile/who-we-are/

Overdrive. (2021, January 26). Borrowing Kindle books from your library. Retrieved March 29, 2021 from https://help.overdrive.com/enus/0431.html

Puacz, J. H. (2005). Electronic vs. print reference Balancing print and electronic collections sources in public library collections. Reference Librarian, 91/92, 39-51.

Rao, K. N., Tripathi, M., \& Kumar, S. (2016). Cost of Print and Digital Books: A Comparative Study. The Journal of Academic Librarianship, 42(4), 445-452.

Sendze, M. (2012). The e-book experiment. Public Libraries, 51(1), 34-37.

Terrell, H.B. (2015) Reference is dead, long live reference: Electronic collections in the digital age. Information Technology and Libraries, 34(4), 55-62.

Tribune Wire Reports (2015, July 12). Some libraries struggle to find balance between print, digital. Chicago Tribune. Retrieved from https://www.chicagotribune.com/enter tainment/books/ct-libraries-printbooks-ebooks-20150708-story.html 